Article

\title{
Neutral Lipids, Glycolipids, and Phospholipids, Isolated from Sandfish (Arctoscopus japonicus) Eggs, Exhibit Anti-Inflammatory Activity in LPS-Stimulated RAW264.7 Cells through NF- $\kappa B$ and MAPKs Pathways
}

\author{
Weerawan Rod-in ${ }^{1}$, Chaiwat Monmai ${ }^{1,2}{ }^{\mathbb{D}}$, Il-sik Shin ${ }^{1}$, SangGuan You ${ }^{1,2}$ and \\ Woo Jung Park 1,2 ,* \\ 1 Department of Marine Biotechnology, Gangneung-Wonju National University, Gangneung, Gangwon 25457, \\ Korea; kae_ve@hotmail.com (W.R.-i.); bbuayy@gmail.com (C.M.); shinis@gwnu.ac.kr (I.-s.S.); \\ umyousg@gwnu.ac.kr (S.Y.) \\ 2 East Coast Life Sciences Institute, Gangneung-Wonju National University, Gangneung, \\ Gangwon 25457, Korea \\ * Correspondence: pwj0505@gwnu.ac.kr; Tel.: +82-33-640-2857; Fax: +82-33-640-2850
}

Received: 31 July 2020; Accepted: 18 September 2020; Published: 21 September 2020

\begin{abstract}
Total lipids were extracted from sandfish (Arctoscopus japonicus), and then they were separated into the following three lipid fractions: neutral lipids, glycolipids, and phospholipids. In this study, we analyzed the lipid fractions of A. japonicus eggs and we determined their anti-inflammatory activity in RAW264.7 macrophage cells. In these three lipid-fractions, the main fatty acids were as follows: palmitic acid (16:0), oleic acid (18:1n-9), docosahexaenoic acid (DHA, 22:6n-3), and eicosapentaenoic acid (EPA, 20:5n-3). Among the lipid fractions, phospholipids showed the highest concentration of DHA and EPA ( $21.70 \pm 1.92$ and $18.96 \pm 1.27$, respectively). The three lipid fractions of $A$. japonicus significantly suppressed the production of $\mathrm{NO}$ in macrophages. Moreover, they also significantly inhibited the expression of $i N O S, C O X-2, I L-6, I L-1 \beta$, and TNF- $\alpha$, in a dose-dependent manner. Furthermore, the lipid fractions of $A$. japonicus suppressed the nuclear translocation of NF- $\mathrm{BB}$ p65 subunits in a dose-dependent manner. In addition, they attenuated the activation of MAPKs (p38, ERK1/2, and JNK) phosphorylation in LPS-stimulated RAW264.7 cells. These results indicate that all the lipid fractions of $A$. japonicus exert anti-inflammatory activity by suppressing the activation of NF- $\mathrm{KB}$ and MAPK pathways. Therefore, the lipid fractions of $A$. japonicus might be potentially used as anti-inflammatory agents.
\end{abstract}

Keywords: Arctoscopus japonicus; lipid; polyunsaturated fatty acids; anti-inflammatory; NF- $\mathrm{B}$ pathway; MAPK

\section{Introduction}

Fish eggs contain many nutrients, such as amino acids, lipids, vitamins, and minerals. Lipids perform many important structural and functional roles in cell membranes. Moreover, lipids are a major source of energy during embryonic and early developmental stages of larvae. In addition, lipids are a major source of essential fatty acids, which play a pivotal role in the growth, reproductive functions, and in the maintenance of healthy tissues [1,2]. Based on their chemical characteristics, lipids can be divided in two major classes: neutral lipids (triacylglycerols (TAGs), waxes, and terpenes), and polar lipids (phospholipids, glycolipids, sphingolipids, etc.) [3]. Neutral lipids are also known as reserve lipids, which are used as a major source of energy [4,5]. On the other hand, polar lipids 
are important components of the cell membrane. Some of them can serve as a source of energy while participating in cell signaling and cell-cell interactions $[3,6]$. For example, glycolipids are membrane lipids that act as cellular markers, and they also participate in cell adhesion, signal transduction, cell-cell interaction, and recognition [7]. Moreover, phospholipids are essential components for the developing eggs in fish, and they also serve as a source of energy during the embryonic and early stages of larval development [8].

Fish lipids are rich in polyunsaturated fatty acids (PUFAs), which act as precursors of lipid mediators and regulate inflammation and immune responses [9]. In particular, eicosapentaenoic acid (EPA, 20:5n-3) and docosahexaenoic acid (DHA, 22:6n-3) are found to be in high concentrations in various species of fish, such as herring [10-12], tuna [13], sea bream [14], beluga [15], rainbow trout [16], salmon [12,17,18], boarfish [12], and teleost [2]. Both EPA and DHA exert beneficial effects on various inflammatory diseases, such as Alzheimer's disease [19], cardiovascular diseases [20], cancer [21,22], diabetes $[23,24]$, thrombosis $[12,17,18]$, and inflammatory activity $[25,26]$. A recent research study has reported that when n-3 PUFA binds with polar lipids, it exerts differential bioavailability and biological effects upon consumption in contrast to neutral forms of n-3 PUFA [27]. Similarly, in vivo studies have also found that when n-3 PUFA binds with polar lipids, it becomes more bioavailable and bioactive than n-3 PUFA bound to TAG [28].

Lipopolysaccharide (LPS)-stimulated macrophages release inflammatory mediators, such as nitric oxide $(\mathrm{NO})$ and prostaglandin $\mathrm{E}_{2}\left(\mathrm{PGE}_{2}\right)$. These compounds induce the expression of immune regulated enzymes, such as nitric oxide synthases (iNOS) and cyclooxygenase-2 (COX-2). Moreover, they also induce the expression of pro-inflammatory cytokines, such as interleukin-1 $\beta$ (IL-1 $\beta)$, IL-6, and tumor necrosis factor (TNF) $\alpha$. These cytokines play a pivotal role in eliciting pathogenic inflammatory responses [29]. However, omega-3 fatty acids can inhibit the product of cytokines in LPS-activated human monocytes and murine RAW264.7 macrophages [30-33]. In LPS-stimulated macrophages, omega-3 fatty acids block the activity of pro-inflammatory transcription factor, such as nuclear factor $\kappa \mathrm{B}(\mathrm{NF}-\mathrm{\kappa B}),[26,31,33]$ and suppress the activity of mitogen-activated protein kinases (MAPKs) $[26,34]$.

Sandfish (Arctoscopus japonicus) is a cold-water fish, which is found in the Northwestern Pacific Ocean and, in the east coast of Korea [35,36]. It has been found that A. japonicus eggs exhibit antioxidant activity $[37,38]$ and anti-inflammatory activity of peptides, which are derived from enzymatic hydrolysates on RAW264.7 cells [39,40]. Ishihara and Watanabe [41] reported that Japanese sandfish eggs predominantly contained the following fatty acids: palmitic acid, oleic acid, DHA, and EPA. In our preliminary research study, we found that total lipids of $A$. japonicus eggs had high amounts of PUFAs (52.9\% of the total fatty acid content; the predominant compounds were DHA [25.9 $\pm 0.1 \%$ ] and EPA $[21.2 \pm 0.5 \%])$. Furthermore, it was found that total lipids exhibit anti-inflammatory activity on macrophages [42]. However, no previous study has examined the fatty acid profiles of individual lipids, which were isolated from A. japonicus eggs by fractional distillation. Moreover, no previous study has determined how these lipid-fractions exert anti-inflammatory activity on macrophages. Therefore, the present study was conducted to determine the fatty acid composition of fractionated lipids, which were isolated from $A$. japonicus eggs. These lipid fractions were composed of neutral lipids, glycolipids, and phospholipids. In this study, we also investigated how these lipid fractions exerted anti-inflammatory activity on LPS-stimulated RAW264.7 macrophages.

\section{Results}

2.1. Fatty Acid Analysis of A. japonicus Lipid-Fractions (Neutral Lipids, Glycolipids, and Phospholipids), Which were Isolated from A. japonicus Eggs

Gas chromatography (GC)-flame ionization detection (FID) method was used to determine the composition of fatty acids in lipid fractions, which were isolated from A. japonicus eggs. These lipid fractions contained neutral lipids, glycolipids, and phospholipids. Table 1 presents the composition of fatty acids in the lipid fractions derived from A. japonicus eggs. In all the lipid fractions, the most abundant saturated fatty acids (SFAs) were palmitic acid (16:0). Its composition in different lipid 
fractions was as follows: neutral lipids $(33.17 \pm 0.28)$, glycolipids $(26.30 \pm 0.27)$, and phospholipids $(19.01 \pm 1.27 \%)$. In neutral lipids and glycolipids, monounsaturated fatty acids (MUFAs) were the most abundant form of fatty acids (FAs). The concentration of MUFAs in neutral lipids and glycolipids was found to be $46.80 \pm 0.79$ and $38.68 \pm 0.26 \%$, respectively. In contrast, polyunsaturated fatty acids (PUFAs) were the most abundant FAs in phospholipids. The concentration of PUFAs in phospholipids $(46.86 \pm 3.40 \%)$ was found to be significantly higher than that in neutral lipids $(16.20 \pm 0.70 \%)$ and glycolipids $(28.79 \pm 0.58 \%)$. Among the PUFAs, long chain omega-3 fatty acids, such EPA and DHA, were found in high concentrations in phospholipids, followed by glycolipids and neutral lipids, respectively.

Table 1. Fatty acid composition (wt.\%) of fractionated lipids from A. japonicus eggs.

\begin{tabular}{cccc}
\hline Fatty Acid & Neutral Lipids & Glycolipids & Phospholipids \\
\hline Saturated fatty acid (SFA) & & & \\
$16: 0$ & $33.17 \pm 0.28^{\mathrm{aA}}$ & $26.30 \pm 0.27^{\mathrm{aB}}$ & $19.01 \pm 1.27^{\mathrm{bC}}$ \\
$18: 0$ & $3.82 \pm 0.05^{\mathrm{fB}}$ & $6.23 \pm 0.06^{\mathrm{gA}}$ & $6.23 \pm 0.42^{\mathrm{eA}}$ \\
\hline Total SFAs & $37.00 \pm 0.31$ & $32.53 \pm 0.33$ & $25.24 \pm 1.68$ \\
\hline Monounsaturated fatty acid (MUFA) & & \\
$16: 1 \mathrm{n} 7$ & $9.874 \pm 0.28^{\mathrm{cA}}$ & $7.51 \pm 0.05^{\mathrm{fB}}$ & - \\
$18: 1 \mathrm{n} 9$ & $25.94 \pm 0.50^{\mathrm{bA}}$ & $22.18 \pm 0.23^{\mathrm{bB}}$ & $15.83 \pm 1.00^{\mathrm{cC}}$ \\
$18: 1 \mathrm{n} 7$ & $10.07 \pm 0.14^{\mathrm{cB}}$ & $8.98 \pm 0.02^{\mathrm{eC}}$ & $12.07 \pm 0.73^{\mathrm{dA}}$ \\
20:1 & $1.05 \pm 0.06^{\mathrm{hA}}$ & - & - \\
\hline Total MUFAs & $46.80 \pm 0.79$ & $38.68 \pm 0.26$ & $27.89 \pm 1.73$ \\
\hline Polyunsaturated fatty acid (PUFA) & & - \\
$18: 2 \mathrm{n} 6$ (LA) & $1.14 \pm 0.02^{\mathrm{hA}}$ & - & - \\
18:3n3 (ALA) & $0.44 \pm 0.02^{\mathrm{iA}}$ & & \\
20:3n3 & $1.99 \pm 0.08^{\mathrm{gC}}$ & $3.49 \pm 0.06^{\mathrm{hB}}$ & $6.21 \pm 0.25^{\mathrm{eA}}$ \\
20:5n3 (EPA) & $7.83 \pm 0.35^{\mathrm{dC}}$ & $12.07 \pm 0.21^{\mathrm{dB}}$ & $18.96 \pm 1.27^{\mathrm{bA}}$ \\
22:6n3 (DHA) & $4.80 \pm 0.65^{\mathrm{eC}}$ & $13.23 \pm 0.33^{\mathrm{cB}}$ & $21.70 \pm 1.92^{\mathrm{aA}}$ \\
\hline Total PUFAs & $16.20 \pm 0.70$ & $28.79 \pm 0.58$ & $46.86 \pm 3.40$ \\
\hline
\end{tabular}

Results are presented as means $\pm \mathrm{SD}(n=5)$. The letters (a-i) indicate significant differences $(p<0.05)$ between the amounts of fatty acids, which were obtained from the same A. japonicus lipid-fractions. The letters (A-C) indicate significant differences $(p<0.05)$ between the amounts of fatty acids, which were obtained from different A. japonicus lipid-fractions.

2.2. The Cytotoxicity of A. japonicus Lipid-Fractions (Neutral Lipids, Glycolipids, and Phospholipids) against RAW264.7 Cells

We evaluated the cytotoxic effects of the three fractionated lipids, namely, neutral lipids, glycolipids, and phospholipids, which were derived from A. japonicus eggs. For this purpose, we cultured RAW264.7 cells in different concentrations of lipid fractions. Thereafter, the EZ-Cytox Cell Viability Assay Kit was used to measure the proliferation of cells. Figure 1 shows that unlike the negative control, neutral lipids, and phospholipids showed no cytotoxicity up to a concentration of 2.0\%. Glycolipids also showed no cytotoxicity when they were present in low concentrations of $0.5 \%$ and $1.0 \%$ in lipids; however, they showed slight cytotoxicity at higher concentrations of $1.5 \%$ and $2 \%$. Nevertheless, the cytotoxicity of glycolipids was slightly lower than that of the negative control. 


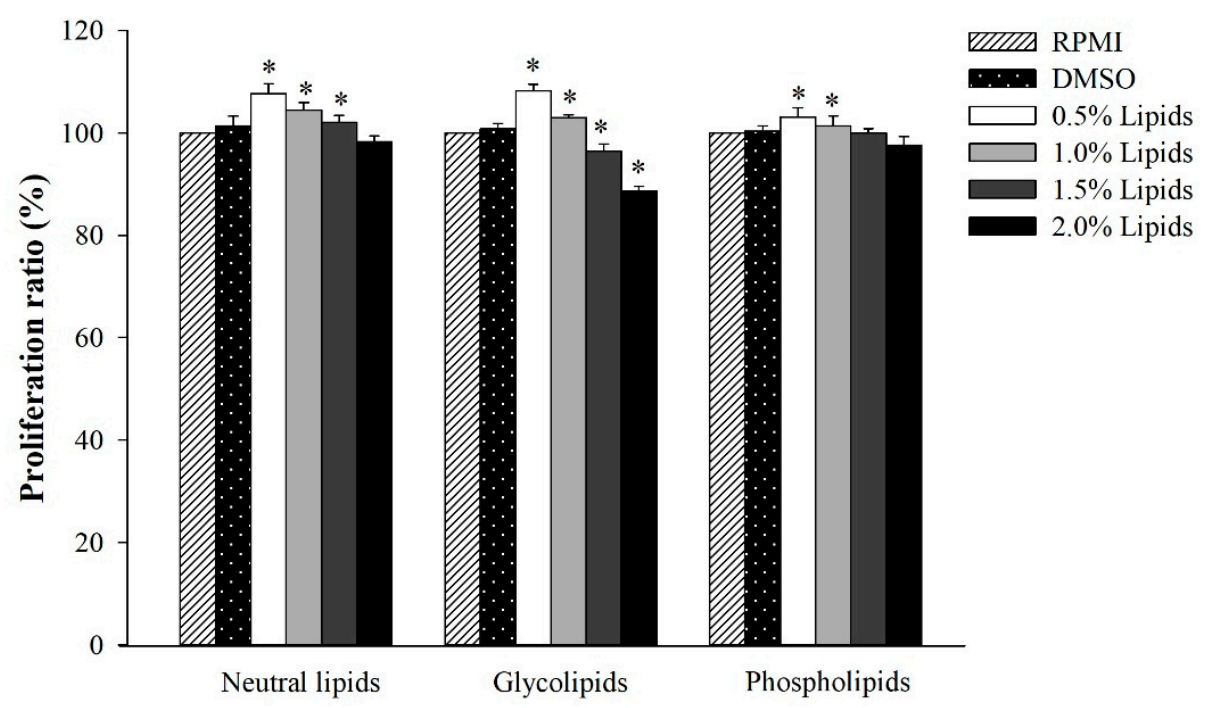

Figure 1. The effect of A. japonicus lipid-fractions (neutral lipids, glycolipids and phospholipids) on cell proliferation in RAW264.7 cells. The data were presented as the mean \pm SD of three independent experiments. Significant difference was observed at $p<0.05\left(^{*}\right)$ when compared with RPMI medium.

2.3. The Anti-Inflammatory Effect of A. japonicus Lipid-Fractions (Neutral Lipids, Glycolipids, and Phospholipids) against NO Production in LPS-Stimulated RAW264.7 Cells

After isolating the three lipid fractions from A. japonicus eggs, we determined their anti-inflammatory activity by measuring the concentration of accumulated nitrite in the culture medium. Griess reagent assay was performed for this purpose. As shown in Figure 2, RAW264.7 cells were treated with various concentrations of each lipid fraction, and the concentration of NO was determined in LPS-stimulated macrophage cells. Our results indicate that neutral lipids, glycolipids, and phospholipids significantly decreased the production of NO in LPS-stimulated RAW264.7 cells in a dose-dependent manner.

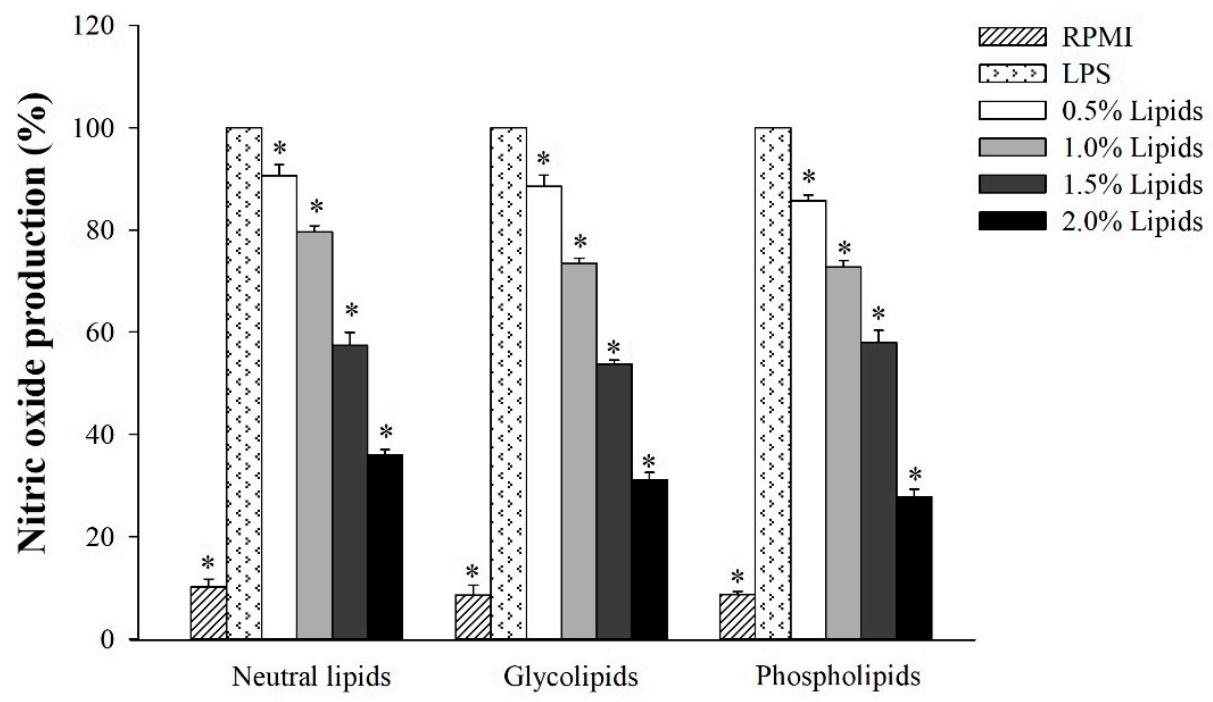

Figure 2. The effect of $A$. japonicus lipid-fractions (neutral lipids, glycolipids and phospholipids) on the production of nitric oxide (NO) in lipopolysaccharide (LPS)-stimulated RAW264.7 cells. The data were presented as mean \pm SD of three independent experiments. A significant difference was observed at $p<0.05\left(^{*}\right)$ when compared with LPS. 
2.4. The Anti-Inflammatory Effect of A. japonicus Lipid Fractions (Neutral Lipids, Glycolipids, and Phospholipids) against Immune-Associated Gene Expression in LPS-Stimulated RAW264.7 Cells

To investigate whether lipid fractions of A. japonicus eggs have anti-inflammatory effects, we analyzed the expression of immune-associated genes by performing real-time quantitative PCR on RAW264.7 cells. Thus, we determined the gene expression level of neutral lipids (Figure 3A), glycolipids (Figure 3B), and phospholipids (Figure 3C). In particular, inflammatory mediator genes, such as $i N O S$ and COX-2, had significantly decreased expression in the lipid fractions of $A$. japonicus eggs. Moreover, the expression of pro-inflammatory cytokine genes, such as $I L-1 \beta, T N F-\alpha$, and $I L-6$, was also inhibited in a dose-dependent manner. However, cell-specific gene expression was slightly and differentially inhibited depending on the concentration of lipid fractions derived from A. japonicus.

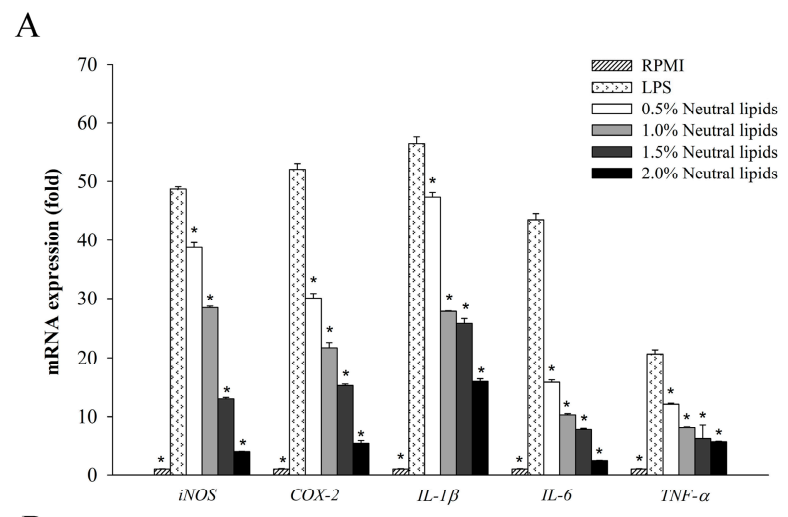

B

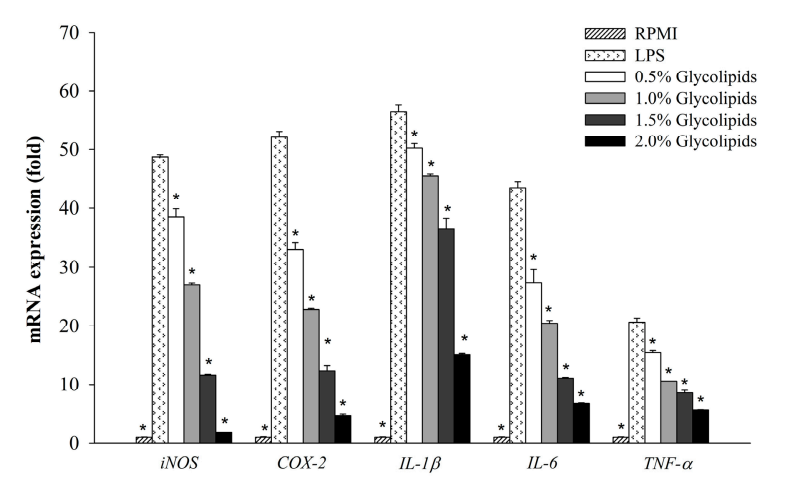

C

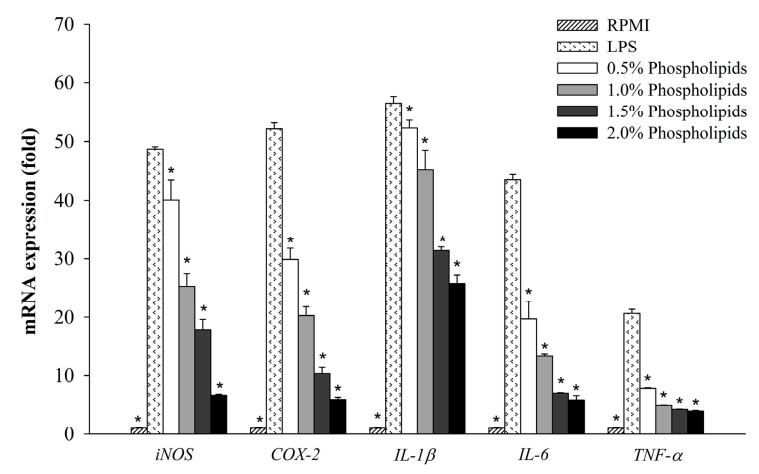

Figure 3. The effect of $A$. japonicus lipid-fractions (neutral lipids, glycolipids and phospholipids) on immune-associated gene expression in LPS-stimulated RAW264.7 cells. (A) The relative mRNA expression of neutral lipids; (B) The relative mRNA expression of glycolipids; (C) The relative mRNA expression of phospholipids. The data were presented as mean $\pm \operatorname{SD}(n=3)$. A significant difference was observed at $p<0.05$ when compared with LPS $\left(^{*}\right)$. 
2.5. The Anti-Inflammatory Effects of A. japonicus Lipid Fractions (Neutral Lipids, Glycolipids, and Phospholipids) on the NF- $\mathrm{KB}$ and MAPKs Signaling Pathways of LPS-Stimulated RAW264.7 Cells

To further investigate whether the lipid fractions of $A$. japonicus exhibited anti-inflammatory activity in LPS-stimulated RAW264.7 cells, we determined the protein expression levels of LPS-induced phosphorylation of MAPKs and NF-kB-p65 pathways in RAW264.7 cells by performing western blot analysis. Figure 4 shows that neutral lipids (Figure 4A,B), glycolipids (Figure 4C,D), and phospholipids (Figure 4E,F) suppressed the phosphorylation of NF-kB p65 subunit in a dose-dependent manner, when compared to that in the control.

A

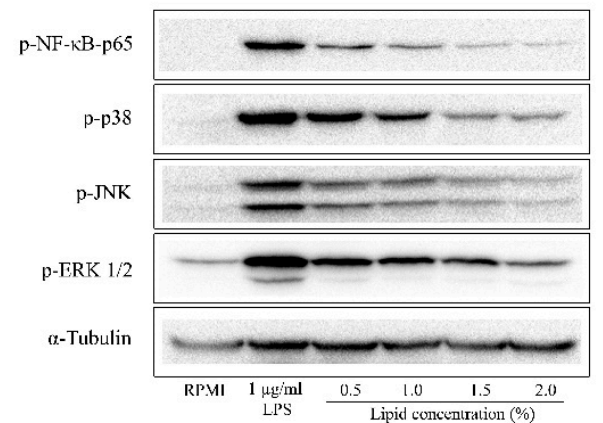

C

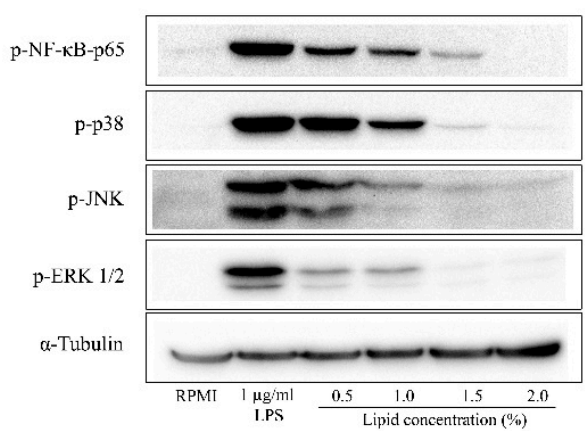

E

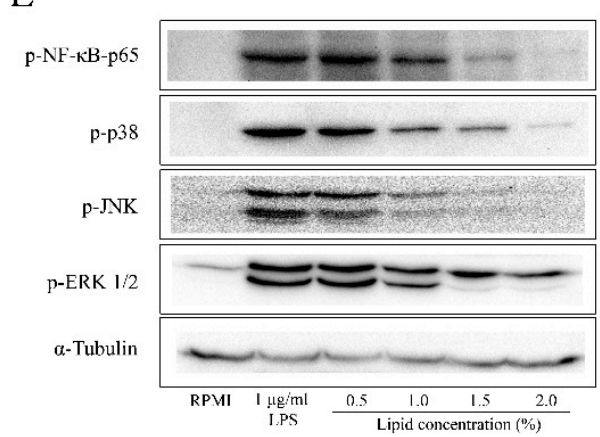

B

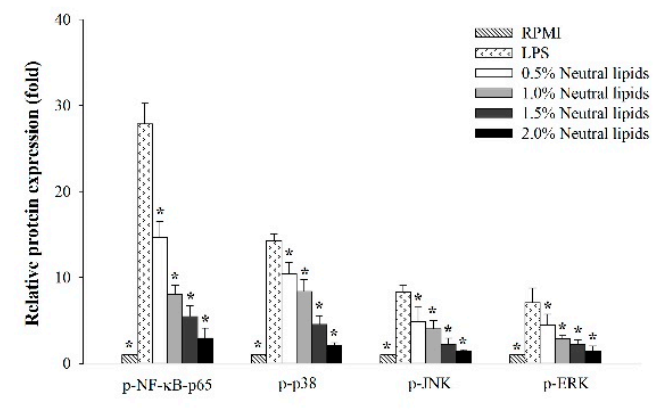

D

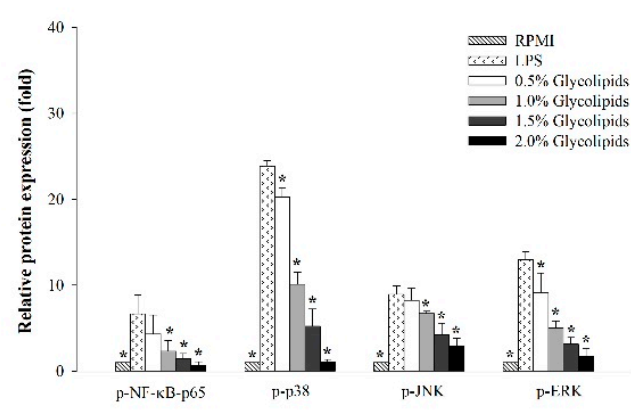

$\mathrm{F}$

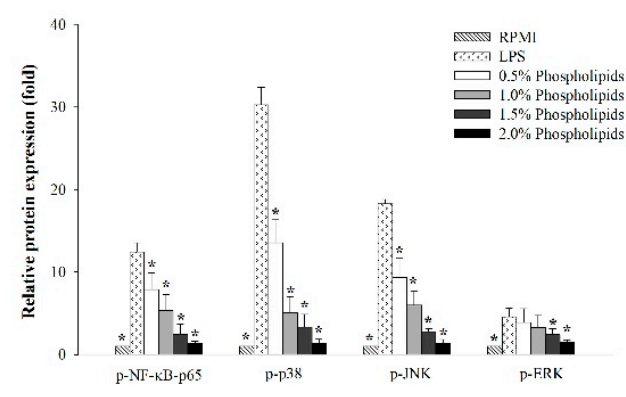

Figure 4. Western blot analysis was performed to determine the effect of lipid fractions (neutral lipids, glycolipids and phospholipids) of A. japonicus on the expression of proteins associated with NF- $\mathrm{B}$ and MAPK pathways in LPS-stimulated RAW264.7 cells. (A) Western blot analysis of neutral lipids; (B) The relative protein expression of neutral lipids; (C) Western blot analysis of glycolipids; (D) The relative protein expression of glycolipids; (E) Western blot analysis of phospholipids; (F) The relative protein expression of phospholipids. The data were presented as mean $\pm \mathrm{SD}(n=3)$. A significant difference was observed at $p<0.05$ when compared with LPS $\left(^{*}\right)$.

All the lipid fractions of $A$. japonicus eggs could also inhibit the activation of phosphorylated ERK, JNK, and p38, which are the biomarkers of the MAPK signaling pathway. 


\section{Discussion}

Previous studies have shown that EPA (21.2\%) and DHA (25.9\%) were abundantly present in the total lipids extracted from $A$. japonicus eggs. Moreover, the lipid fractions exhibited anti-inflammatory activity by inhibiting the activity of NF- $\mathrm{kB}$ and MAPKs signaling pathways in LPS-stimulated mouse macrophages [42]. In this study, total lipids were extracted from A. japonicus eggs and were subjected to fractional distillation. Thus, we obtained the following three lipid fractions: neutral lipids, glycolipids, and phospholipids. Furthermore, we investigated these lipid fractions to determine whether they exhibit anti-inflammatory activity.

The composition of fatty acids in lipid fractions was determined by GC-FID method. Our results indicate that the three lipid fractions, namely, neutral lipids, glycolipids, and phospholipids contained different kinds of fatty acids, such as SFAs, MUFAs, and PUFAs in different ratios (Table 1). In previous literature studies, it has been reported that palmitic acid (16:0) and oleic acid (18:1n-9) were the major fatty acids in herring eggs, and they were further classified as SFAs and MUFAs, respectively. These fatty acids are essential sources of metabolic energy in fish [10]. Likewise, EPA (20:5n-3), DHA (22:6n-3), palmitic acid (16:0), and oleic acid (18:1n-9) were the major constituents of lipid fractions isolated from several fish eggs [11,43-46]. Although previous studies were based on Atlantic salmon and fish roes, their results were similar to those obtained in this study [11,47]. Thus, neutral lipids and glycolipids that were isolated from A. japonicus eggs had the highest concentration of MUFAs, while phospholipids were composed of a large amount of PUFAs. In particular, we also observed that EPA and DHA were present in significant amounts in phospholipids. Moreover, EPA and DHA were also predominantly present in other lipid fractions. Interestingly, EPA and DHA are the omega-3 PUFAs that play a pivotal role in eliciting anti-inflammatory responses [48]. The lipid extracts obtained from fish had the highest amount of omega-3 PUFAs, and they exhibited maximum anti-inflammatory activity by stimulating immune cells, such as macrophages. Thus, these lipid extracts were useful in suppressing inflammatory responses $[9,48]$. Furthermore, it has been found that DHA is more effective than EPA in suppressing LPS-induced production of pro-inflammatory cytokines in macrophages [32]. Marine polar lipids are rich in omega-3 PUFAs, which exhibit strong anti-inflammatory activity and antithrombotic effects on the inflammatory and thrombotic mediators of platelet-activating factor (PAF) and thrombin $[12,17,18,49]$. Apart from PAF and thrombin, several inflammatory responses are characterized by the release of other critical inflammatory mediators, such as NO and several prostaglandins like $\mathrm{PGE}_{2}$.

The inflammatory responses are associated with the release of critical inflammatory mediators, such as $\mathrm{NO}$ and $\mathrm{PGE}_{2}$. The expression of these mediators is regulated by iNOS and COX-2, respectively, and pro-inflammatory cytokines [50]. Ahmad et al. [51] reported that they extracted lipids from Australian seafood organisms, such as octopus, squid, sardine, salmon, and school prawns. These lipid extracts performed immunomodulatory actions, such as the inhibition of NO and TNF- $\alpha$ production in LPS-stimulated RAW264.7 cells. Similarly, the lipid extracts isolated from blue-green alga (Nostoc commune) significantly reduced the expression of TNF- $\alpha, I L-1 \beta, I L-6, C O X-2$, and $i N O S$ in LPS-stimulated macrophages by inhibiting the activation of NF- $k B$ pathway [52]. Skipjack tuna eyeball oil also exerts anti-inflammatory effects by inhibiting the activity of NF- $\mathrm{KB}$ and MAPKs pathways in LPS-induced RAW264.7 cells [53].

Diverse marine organisms exhibit immune biological activities. In this study, we found that the lipid fractions of A. japonicus had remarkably suppressed the production of NO in LPS-stimulated macrophage cells (Figure 2). Moreover, the lipid fractions of $A$. japonicus also inhibited the activity of NO by downregulating the expression of $i N O S$ and COX-2, which are found to be associated with the secretion of $\mathrm{NO}$ and $\mathrm{PGE}_{2}$. Thus, the lipid fractions of $A$. japonicus suppressed the expression of pro-inflammatory cytokines (Figure 3). This is because pro-inflammatory cytokines such as TNF- $\alpha$, IL-6, and IL-1 $\beta$ play an important role in eliciting immune responses to a variety of inflammatory stimuli. In this study, the three lipid fractions of A. japonicus significantly inhibited the LPS-stimulated mRNA expression of these pro-inflammatory cytokines in a dose-dependent manner (Figure 3). Chen et al. [54] 
isolated four lipid fractions, namely, total lipids, neutral lipids, glycolipids, and phospholipids from seahorse (Hippocampus trimaculatus). They found that these lipid fractions could inhibit the production of NO, IL-6, IL-1 $\beta$, and TNF- $\alpha$. The marine neutral lipids, for example, sterols isolated from Dendronephthya gigantean exhibited a significant anti-inflammatory activity by inhibiting the production of $\mathrm{NO}$ and $\mathrm{PGE}_{2}$. Moreover, they also suppressed the expression of pro-inflammatory cytokines, such as TNF- $\alpha, I L-1 \beta$, and IL-6 in LPS-stimulated RAW264.7 macrophages in a dose-dependent manner [55]. Meanwhile, polar lipids that were isolated from marine macroalga also suppressed LPS-induced NO production in macrophage cells by downregulating the expression of iNOS [56,57]. Furthermore, glycolipids suppressed LPS-induced vascular inflammation by attenuating the NF-KB pathway and by stimulating the production of NO in endothelial cells [58].

It is well-known that LPS stimulation causes inflammation through several intracellular signaling pathways, such as NF- $\mathrm{kB}$ and MAPK [29]. Moreover, NF- $\mathrm{kB}$ is an important transcription factor that regulates the expression of immune-related cytotoxic factors, such as $i N O S$ and COX-2. In addition, it also suppresses the expression of pro-inflammatory cytokines, such as TNF- $\alpha, I L-1 \beta$, and IL-6 [59]. To determine the underlying mechanism through which the lipid fractions of $A$. japonicus inhibit the nuclear translocation of NF-kB p65, we evaluated the protein levels of NF- $\mathrm{kB}$ p65 in cytosol and nucleus. Figure 4 shows that all kinds of lipid fractions suppressed the phosphorylation of NF-kB p65 in LPS-stimulated RAW264.7 cells. Furthermore, extracellular signal-regulated kinase (ERK), c-Jun $\mathrm{N}$-terminal kinase/stress-activated protein kinase (JNK), and p38, were the MAPKs that played a major role in regulating pro-inflammatory cytokines [60,61]. All the lipid fractions of $A$. japonicus suppressed the LPS-stimulated phosphorylation of p38, ERK1/2, and JNK in a dose-dependent manner (Figure 4). In summary, these results indicate that NF-KB and MAPKs assisted the lipid fractions of A. japonicus in suppressing the production of $\mathrm{NO}$ and pro-inflammatory cytokines in activated macrophages.

\section{Materials and Methods}

\subsection{Lipid Extraction and Separation}

The total lipids of Arctoscopus japonicus eggs were extracted from a freeze-dried powder by using the Bligh and Dyer method (1959) [62]. Briefly, $4.5 \mathrm{~g}$ of the dried sample was homogenized with a mixture of chloroform/methanol (1:2 v/v). Then, we added $10 \mathrm{~mL}$ of chloroform and $10 \mathrm{~mL}$ of distilled water to the reaction mixture, and the blending process was continued for $30 \mathrm{~s}$. In order to separate the two phases of the sample, we centrifuged it at $3000 \mathrm{rpm}$ for $10 \mathrm{~min}$. The chloroform phase was collected and dried under an evaporator. After evaporation, the samples were weighed to estimate the mass of lipids. Then, we dissolved the total lipids in hexane.

The total lipids were separated into different lipid fractions by performing silica gel column chromatography. The column was successively eluted with chloroform, acetone, and methyl alcohol to isolate neutral lipids, glycolipids, and phospholipids, respectively. After separation, the lipid fractions were dried and dissolved in dimethyl sulfoxide (DMSO) to achieve a final concentration of $20 \mathrm{mg} / \mathrm{mL}$ $(w / v)$. Finally, the lipid fractions were stored at $-20^{\circ} \mathrm{C}$ for further analysis.

\subsection{Fatty Acid Analysis}

The Garces and Mancha method was used to extract fatty acids from the three lipid fractions of A. japonicus, namely, neutral lipids, glycolipids, and phospholipids [63]. The three lipid fractions were converted into fatty acid methyl esters (FAMEs) by performing a modified one-step lipid extraction method, which has been described in our previous study [64]. Then, the isolated FAMEs were analyzed by gas chromatography (GC)-flame ionization detection (FID) (Perkin Elmer, Waltham, MA, USA). The experiments were performed in pentaplicates (number of samples for each lipid fraction). The chromatographic peaks of FAMEs were identified by comparing their retention times with the internal standard C17:0 (Sigma-Aldrich, St. Louis, MO, USA). 


\subsection{The Measurement of Cell Proliferation}

In this study, RAW264.7 cells $\left(1 \times 10^{6}\right.$ cells $\left./ \mathrm{mL}\right)$ were cultured for $24 \mathrm{~h}$ in RPMI-1640 medium, which was supplemented with $10 \%$ fetal bovine serum and $1 \%$ penicillin/streptomycin. Thereafter, different concentrations of the three lipid fractions $(0.5 \%, 1.0 \%, 1.5 \%$, and $2.0 \%)$ were treated and incubated for another $24 \mathrm{~h}$. After incubation, the lipid fractions of $A$. japonicus were analyzed with the EZ-Cytox Cell Viability Assay Kit (DaeilLab Service, Seoul, Korea) to determine their cytotoxicity. The procedure has been described in a previous study conducted by Kim et al. [65]. Then, the absorbance of the lipid fractions was measured at $450 \mathrm{~nm}$. The cell proliferation ability was estimated from the following formula:

$$
\text { Proliferation ratio }(\%)=\frac{\text { The absorbance of the sample }}{\text { The absorbance of the control }} \times 100
$$

\subsection{The Measurement of Nitric Oxide (NO) Production}

The cells were treated with different concentrations of each lipid fraction $(0.5 \%, 1.0 \%, 1.5 \%$, and $2.0 \%$ ) for $1 \mathrm{~h}$, and then they were treated with $1 \mu \mathrm{g} / \mathrm{mL}$ lipopolysaccharide (LPS) for $24 \mathrm{~h}$. After stimulation, the NO concentration was estimated in the cultured medium by using Griess reagent (Promega, Madison, WI, USA) [66].

\subsection{Qualitative Real-Time PCR}

Total RNA was extracted from the cells by using the TRI reagent ${ }^{\circledR}$ (Molecular Research Center, Cincinnati, OH, USA). Then, cDNA was synthesized with High-Capacity cDNA Reverse Transcription Kit (Applied Biosystems, Foster City, CA, USA), which was operated according to manufacturer's instructions. To quantify the expression of immune genes, we used the following tools: SYBR ${ }^{\circledR}$ Premix Ex Taq ${ }^{\mathrm{TM}}$ II (Takara Bio Inc., Shiga, Japan) and the QuantStudio ${ }^{\mathrm{TM}} 3$ FlexReal-Time PCR System (ThermoFisher Scientific, Waltham, MA, USA). Table 2 presents the sequences of primers used in this analysis. The expression levels relative to the reference gene $\beta$-Actin were calculated by using the $2^{-\Delta \Delta C T}$ method [67].

Table 2. The primers used in this study.

\begin{tabular}{ccc}
\hline Target Gene & & Sequence (from 5' $^{\prime}$ to $\mathbf{3}^{\prime}$ ) \\
\hline \multirow{2}{*}{ IL-1 $\beta$} & Forward & GGGCCTCAAAGGAAAGAATC \\
& Reverse & TACCAGTTGGGGAACTCTGC \\
iNOS & Forward & TTCCAGAATCCCTGGACAAG \\
& Reverse & TGGTCAAACTCTTGGGGTTC \\
IL-6 & Forward & AGTTGCCTTCTTGGGACTGA \\
& Reverse & CAGAATTGCCATTGCACAAC \\
COX-2 & Forward & AGAAGGAAATGGCTGCAGAA \\
& Reverse & GCTCGGCTTCCAGTATTGAG \\
TNF- $\alpha$ & Forward & ATGAGCACAGAAAGCATGATC \\
& Reverse & TACAGGCTTGTCACTCGAATT \\
$\beta-A c t i n$ & Forward & CCACAGCTGAGAGGAAATC \\
& Reverse & AAGGAAGGCTGGAAAAGAGC \\
\hline
\end{tabular}

\subsection{Western Blot Analysis}

In this experiment, cells were pretreated with different concentrations of lipid fractions of A. japonicus. Then, these cells were stimulated with or without $1 \mu \mathrm{g} / \mathrm{mL}$ of LPS for $24 \mathrm{~h}$. Proteins were extracted from these cells by using RIPA buffer (Tech \& Innovation, Hebei, China). Protein concentrations were determined with Pierce ${ }^{\mathrm{TM}}$ BCA Protein Assay Kit (Thermo Scientific, Waltham, MA, USA). Equal amounts of protein $(30 \mu \mathrm{g})$ were electrophoresed separately by performing sodium dodecyl sulfate-polyacrylamide gel electrophoresis (SDS-PAGE), and then they were transferred 
onto a polyvinylidene fluoride (PVDF) membrane. The membrane was incubated with primary antibodies that specifically identified the following transcription factors: p-NF- $\kappa \mathrm{B}, \mathrm{p} 65, \mathrm{p}-\mathrm{p} 38, \mathrm{p}-\mathrm{JNK}$, and p-ERK1/2 (Cell Signaling Technology, Danvers, MA, USA), and $\alpha$-tubulin (Abcam, Cambridge, $\mathrm{UK})$. After washing the membrane, the bolts were incubated with Goat Anti-Rabbit IgG (H + L)-HRP (GenDEPOT, Katy, TX, USA) at $37^{\circ} \mathrm{C}$ for $1 \mathrm{~h}$. The bands were visualized with the following tools: Pierce ${ }^{\circledR}$ ECL Plus Western Blotting Substrate (Thermo Scientific, Waltham, MA, USA), ChemiDoc XRS+ imaging system, and ImageLab software (Bio-Rad, Hercules, CA, USA).

\subsection{Statistical Analysis}

The results were expressed as mean \pm standard deviation (SD). Significant differences were determined by performing a one-way analysis of variance (ANOVA) test with the help of SPSS software (Version 24, SPSS Inc, Chicago, IL, USA). The results were further analyzed by Duncan's multiple-range test. The values at $p<0.05$ were considered to be statistically significant.

\section{Conclusions}

The composition of fatty acids was determined in the three kinds of lipid fractions isolated from A. japonicus eggs. All the lipid fractions of A. japonicus contained a large amount of omega- 3 PUFAs like EPA and DHA, which have several beneficial effects on human health. The present results indicate that lipid fractions of $A$. japonicus can effectively inhibit the production of NO in a dose-dependent manner. Moreover, these lipid fractions not only suppressed the expression of pro-inflammatory cytokines, such as TNF- $\alpha, I L-6$, and IL-1 $\beta$ but also of pro-inflammatory mediators such as $i N O S$ and COX-2 in LPS-stimulated RAW264.7 cells. Furthermore, the lipid fractions of A. japonicus exhibited anti-inflammatory activity by suppressing the activity of NF- $\mathrm{kB}$ and MAPKs in LPS-stimulated macrophages. Therefore, the three lipid fractions of $A$. japonicus, namely neutral lipids, glycolipids, and phospholipids, could be potentially used as anti-inflammatory agents in the treatment of inflammatory diseases.

Author Contributions: W.R.-i. designed and performed the experiments, analyzed the data, and wrote the manuscript. C.M. only designed and performed the experiments. I.-s.S., and S.Y. edited the manuscript. W.J.P. designed the experiment, analyzed the data, and wrote the manuscript. The authors that contributed to this research study are as follows: "conceptualization, C.M. and W.J.P.; methodology, W.R.-i.; software, W.R.-i. and C.M.; validation, W.R.-i. and C.M.; formal analysis, W.R.-i. and C.M.; investigation, W.R.-i.; resources, W.J.P.; data curation, W.R.-i., C.M., and W.J.P.; writing - original draft preparation, W.R.; writing-review and editing, I.-s.S., S.Y., and W.J.P.; visualization, W.R.-i. and C.M.; supervision, W.J.P.; project administration, W.J.P.; funding acquisition, W.J.P." All authors have read and agreed to the published version of the manuscript.

Funding: This study was partially supported by the Marine Bio-Regional Specialization Leading Technology Development Program (D11413914H480000100), which is funded by the Ministry of Oceans and Fisheries in Korea. The authors also received grants from the Basic Science Research Program of the National Research Foundation of Korea (NRF), which is funded by the Ministry of Science, ICT \& Future Planning (2019R1A2B5B01070542). This research project is also supported by the University Emphasis Research Institute Support Program (No.2018R1A61A03023584), which is funded by the National Research Foundation of Korea.

Conflicts of Interest: The authors declare no conflict of interest.

\section{References}

1. $\quad$ Sargent, J.R.; Tocher, D.R.; Bell, J.G. 4-The Lipids. In Fish Nutrition, 3rd ed.; Halver, J.E., Hardy, R.W., Eds.; Academic Press: San Diego, CA, USA, 2003; pp. 181-257.

2. Tocher, D.R. Metabolism and functions of lipids and fatty acids in teleost fish. Rev. Fish Sci. 2003, 11, 107-184. [CrossRef]

3. Lordan, R.; Tsoupras, A.; Zabetakis, I. Phospholipids of animal and marine origin: Structure, function, and anti-inflammatory properties. Molecules 2017, 22, 1964. [CrossRef] [PubMed]

4. Henderson, R.J.; Tocher, D.R. The lipid composition and biochemistry of freshwater fish. Prog. Lipid Res. 1987, 26, 281-347. [CrossRef] 
5. Hutchins, P.M.; Barkley, R.M.; Murphy, R.C. Separation of cellular nonpolar neutral lipids by normal-phase chromatography and analysis by electrospray ionization mass spectrometry. J. Lipid Res. 2008, 49, 804-813. [CrossRef]

6. Lim, S.Y.; Park, W.K.; Suzuki, H. Analyses of glycolipids from fish, shellfish, and sea snake lipids by high-performance liquid chromatography. J. Agric. Food Chem. 1999, 47, 960-963. [CrossRef]

7. Malhotra, R. Membrane glycolipids: Functional heterogeneity: A review. Biochem. Anal. Biochem. 2012, 1, 1000108. [CrossRef]

8. Tocher, D.R.; Bendiksen, E.Å.; Campbell, P.J.; Bell, J.G. The role of phospholipids in nutrition and metabolism of teleost fish. Aquaculture 2008, 280, 21-34. [CrossRef]

9. Wall, R.; Ross, R.P.; Fitzgerald, G.F.; Stanton, C. Fatty acids from fish: The anti-inflammatory potential of long-chain omega-3 fatty acids. Nutr. Rev. 2010, 68, 280-289. [CrossRef]

10. Huynh, M.D.; Kitts, D.D.; Hu, C.; Trites, A.W. Comparison of fatty acid profiles of spawning and non-spawning Pacific herring, Clupea Harengus pallasi. Comp. Biochem. Physiol. B. Biochem. Mol. Biol. 2007, 146, 504-511. [CrossRef]

11. Moriya, H.; Hosokawa, M.; Miyashita, K. Combination effect of herring roe lipids and proteins on plasma lipids and abdominal fat weight of mouse. J. Food Sci. 2007, 72, 231-234. [CrossRef]

12. Tsoupras, A.; O'Keeffe, E.; Lordan, R.; Redfern, S.; Zabetakis, I. Bioprospecting for antithrombotic polar lipids from salmon, herring, and boarfish by-products. Foods 2019, 8, 416. [CrossRef] [PubMed]

13. Garaffo, M.A.; Vassallo-Agius, R.; Nengas, Y.; Lembo, E.; Rando, R.; Maisano, R.; Dugo, G.; Giuffrida, D. Fatty acids profile, atherogenic (IA) and thrombogenic (IT) health lipid indices, of raw roe of Blue Fin Tuna (Thunnus thynnus L.) and their salted product "Bottarga". Food Nutr. Sci. 2011, 2, 736-743.

14. Torrecillas, S.; Montero, D.; Domínguez, D.; Robaina, L.; Izquierdo, M. Skin mucus fatty acid composition of gilthead sea bream (Sparus aurata): A descriptive study in fish fed low and high fish meal diets. Fishes 2019, 4, 15. [CrossRef]

15. Ovissipour, M.; Rasco, B. Fatty acid and amino acid profiles of domestic and wild beluga (Huso huso) roe and impact on fertilization ratio. J. Aquac. Res. Dev. 2011, 2. [CrossRef]

16. Mahmoud, K.A.S.; Linder, M.; Fanni, J.; Parmentier, M. Characterisation of the lipid fractions obtained by proteolytic and chemical extractions from rainbow trout (Oncorhynchus mykiss) roe. Process Biochem. 2008, 43, 376-383. [CrossRef]

17. Tsoupras, A.; Lordan, R.; Demuru, M.; Shiels, K.; Saha, S.K.; Nasopoulou, C.; Zabetakis, I. Structural elucidation of Irish organic farmed salmon (Salmo salar) polar lipids with antithrombotic activities. Mar. Drugs 2018, 16, 176. [CrossRef]

18. Tsoupras, A.; Lordan, R.; Shiels, K.; Saha, S.K.; Nasopoulou, C.; Zabetakis, I. In vitro antithrombotic properties of salmon (Salmo salar) phospholipids in a novel food-grade extract. Mar. Drugs 2019, 17, 62. [CrossRef]

19. Wen, M.; Xu, J.; Ding, L.; Zhang, L.; Du, L.; Wang, J.; Wang, Y.; Xue, C. Eicosapentaenoic acid-enriched phospholipids improve A $\beta 1-40$-induced cognitive deficiency in a rat model of Alzheimer's disease. J. Funct. Foods 2016, 24, 537-548. [CrossRef]

20. Holub, D.J.; Holub, B.J. Omega-3 fatty acids from fish oils and cardiovascular disease. Mol. Cell Biochem. 2004, 263, 217-225. [CrossRef]

21. Molfino, A.; Amabile, M.I.; Lionetto, L.; Spagnoli, A.; Ramaccini, C.; De Luca, A.; Simmaco, M.; Monti, M.; Muscaritoli, M. DHA oral supplementation modulates serum epoxydocosapentaenoic acid (EDP) levels in breast cancer patients. Oxidative Med. Cell. Longev. 2019, 2019, 7. [CrossRef]

22. Paixão, E.M.d.S.; Oliveira, A.C.d.M.; Pizato, N.; Muniz-Junqueira, M.I.; Magalhães, K.G.; Nakano, E.Y.; Ito, M.K. The effects of EPA and DHA enriched fish oil on nutritional and immunological markers of treatment naïve breast cancer patients: A randomized double-blind controlled trial. Nutr. J. 2017, 16, 71. [CrossRef] [PubMed]

23. Li, P.; Zhang, L.; Tian, X.; Xing, J. Docosahexaenoic acid has an anti-diabetic effect in streptozotocin-induced diabetic mice. Int. J. Clin. Exp. Med. 2014, 7, 3021-3029. [PubMed]

24. Vitlov Uljević, M.; Starčević, K.; Mašek, T.; Bočina, I.; Restović, I.; Kević, N.; Racetin, A.; Kretzschmar, G.; Grobe, M.; Vukojević, K.; et al. Dietary DHA/EPA supplementation ameliorates diabetic nephropathy by protecting from distal tubular cell damage. Cell Tissue Res. 2019, 378, 301-317. [CrossRef] [PubMed] 
25. Baker, E.J.; Valenzuela, C.A.; De Souza, C.O.; Yaqoob, P.; Miles, E.A.; Calder, P.C. Comparative anti-inflammatory effects of plant- and marine-derived omega-3 fatty acids explored in an endothelial cell line. BBA-Mol. Cell Biol. 2020, 1865, 158662. [CrossRef] [PubMed]

26. Si, T.L.; Liu, Q.; Ren, Y.F.; Li, H.; Xu, X.Y.; Li, E.H.; Pan, S.Y.; Zhang, J.L.; Wang, K.X. Enhanced anti-inflammatory effects of DHA and quercetin in lipopolysaccharide-induced RAW264.7 macrophages by inhibiting NF-kB and MAPK activation. Mol. Med. Rep. 2016, 14, 499-508. [CrossRef]

27. Lordan, R.; Redfern, S.; Tsoupras, A.; Zabetakis, I. Inflammation and cardiovascular disease: Are marine phospholipids the answer? Food Funct. 2020, 11, 2861-2885. [CrossRef]

28. Murota, K.; Takagi, M.; Watanabe, Y.; Tokumura, A.; Ohkubo, T. Roe-derived phospholipid administration enhances lymphatic docosahexaenoic acid-containing phospholipid absorption in unanesthetized rats. Prostag. Leukotr. Ess. 2018, 139, 40-48. [CrossRef]

29. Guha, M.; Mackman, N. LPS induction of gene expression in human monocytes. Cell. Signal. 2001, 13, 85-94. [CrossRef]

30. Babcock, T.A.; Helton, W.S.; Hong, D.; Espat, N.J. Omega-3 fatty acid lipid emulsion reduces LPS-stimulated macrophage TNF-a production. Surg. Infect. (Larchmt) 2002, 3, 145-149. [CrossRef]

31. Novak, T.E.; Babcock, T.A.; Jho, D.H.; Helton, W.S.; Espat, N.J. NF-kB inhibition by omega -3 fatty acids modulates LPS-stimulated macrophage TNF-a transcription. Am. J. Physiol. Lung Cell. Mol. Physiol. 2003, 284, L84-L89. [CrossRef]

32. Weldon, S.M.; Mullen, A.C.; Loscher, C.E.; Hurley, L.A.; Helen, M.; Roche, H.M. Docosahexaenoic acid induces an anti-inflammatory profile in lipopolysaccharide-stimulated human THP-1 macrophages more effectively than eicosapentaenoic acid. J. Nutr. Biochem. 2007, 18, 250-258. [CrossRef] [PubMed]

33. Zhao, G.; Etherton, T.D.; Martin, K.R.; Vanden Heuvel, J.P.; Gillies, P.J.; West, S.G.; Kris-Etherton, P.M. Anti-inflammatory effects of polyunsaturated fatty acids in THP-1 cells. Biochem. Biophys. Res. Commun. 2005, 336, 909-917. [CrossRef] [PubMed]

34. Lo, C.J.; Chiu, K.C.; Fu, M.; Chu, A.; Helton, S. Fish oil modulates macrophage P44/P42 mitogen-activated protein kinase activity induced by lipopolysaccharide. J. Parenter. Enteral. Nutr. 2000, 24, 159-163. [CrossRef]

35. Lee, S.I.; Yang, J.H.; Yoon, S.C.; Chun, Y.Y.; Kim, J.B.; Cha, H.K.; Choi, Y.M. Biomass estimation of sailfin sandfish, Arctoscopus japonicus, in Korean waters. Korean J. Fish. Aquat. Sci. 2009, 42, 487-493.

36. Shirai, S.M.; Kuranaga, R.; Sugiyama, H.; Higuchi, M. Population structure of the sailfin sandfish, Arctoscopus japonicus (Trichodontidae), in the Sea of Japan. Ichthyol. Res. 2006, 53, 357-368. [CrossRef]

37. Jang, H.L.; Liceaga, A.M.; Yoon, K.Y. Purification, characterisation and stability of an antioxidant peptide derived from sandfish (Arctoscopus japonicus) protein hydrolysates. J. Funct. Foods 2016, 20, 433-442. [CrossRef]

38. Jang, H.L.; Shin, S.R.; Yoon, K.Y. Hydrolysis conditions for antioxidant peptides derived from enzymatic hydrolysates of sandfish (Arctoscopus japonicus). Food Sci. Biotechnol. 2017, 26, 1191-1197. [CrossRef]

39. Jang, H.L.; Liceaga, A.M.; Yoon, K.Y. Isolation and characteristics of anti-inflammatory peptides from enzymatic hydrolysates of sandfish (Arctoscopus japonicus) protein. J. Aquat. Food. Prod. Technol. 2017, 26, 234-244. [CrossRef]

40. Jang, H.L.; Young Yoon, K. Optimal conditions of enzymatic hydrolysis for producing anti-inflammatory peptides from sandfish (Arctoscopus japonicus) hydrolysate. Korean J. Food Sci. Technol. 2018, 50, $203-208$.

41. Ishihara, Y.; Watanabe, F. Lipid content and fatty acid composition of Japanese sandfish Arctoscopus japonicus caught offshore of Tottori Prefecture, Japan. Nippon Suisan Gakk. 2013, 79, 229-231. [CrossRef]

42. Rod-In, W.; Monmai, C.; Lee, S.M.; Jung, S.K.; You, S.; Park, W.J. Anti-inflammatory effects of lipids extracted from Arctoscopus japonicus eggs on LPS-stimulated RAW264.7 cells. Mar. Drugs 2019, 17, 580. [CrossRef] [PubMed]

43. Prabhakara Rao, P.; Balaswamy, K.; Narsing Rao, G.; Jyothirmayi, T. Lipid classes, fatty acid and phospholipid composition of roe lipids from Catla catla and Cirrhinus mrigala. Int. Food Res. J. 2013, 20, 275-279.

44. Prabhakara Rao, P.G.; Jyothirmayi, T.; Karuna, M.S.L.; Prasad, R.B.N. Studies on lipid profiles and fatty acid composition of roe from rohu (Labeo rohita) and murrel (Channa striatus). J. Oleo Sci. 2010, 59, 515-519. [PubMed]

45. Shirai, N.; Higuchi, T.; Suzuki, H. Analysis of lipid classes and the fatty acid composition of the salted fish roe food products, Ikura, Tarako, Tobiko and Kazunoko. Food Chem. 2006, 94, 61-67. [CrossRef] 
46. Majumder, A.; Misra, K.K.; Homechoudhuri, S. Lipid and fatty acid composition in the flesh of an edible marine fish: Amadi (Coilia reynaldi). Proc. Zool. Soc. 2013, 66, 86-91. [CrossRef]

47. Oxley, A.; Torstensen, B.E.; Rustan, A.C.; Olsen, R.E. Enzyme activities of intestinal triacylglycerol and phosphatidylcholine biosynthesis in Atlantic salmon (Salmo salar L.). Comp. Biochem. Physiol. B 2005, 141, 77-87. [CrossRef]

48. Calder, P.C. n-3 polyunsaturated fatty acids, inflammation, and inflammatory diseases. Am. J. Clin. Nutr. 2006, 83, 1505S-1519S. [CrossRef]

49. Nasopoulou, C.; Tsoupras, A.B.; Karantonis, H.C.; Demopoulos, C.A.; Zabetakis, I. Fish polar lipids retard atherosclerosis in rabbits by down-regulating PAF biosynthesis and up-regulating PAF catabolism. Lipids Health Dis. 2011, 10, 213. [CrossRef]

50. Han, Y.; Song, C.; Koh, W.; Yon, G.; Kim, Y.; Ryu, S.; Kwon, H.; Lee, K. Anti-inflammatory effects of the Zingiber officinale roscoe constituent 12-dehydrogingerdione in lipopolysaccharide-stimulated Raw264.7 Cells. Phytother Res. 2013, 27, 1200-1205. [CrossRef]

51. Ahmad, T.B.; Rudd, D.; Kotiw, M.; Liu, L.; Benkendorff, K. Correlation between fatty acid profile and anti-inflammatory activity in common Australian seafood by-products. Mar. Drugs 2019, 17, 155. [CrossRef]

52. Park, Y.K.; Rasmussen, H.E.; Ehlers, S.J.; Blobaum, K.R.; Lu, F.; Schlegal, V.L.; Carr, T.P.; Lee, J.Y. Repression of proinflammatory gene expression by lipid extract of Nostoc commune var sphaeroides Kutzing, a blue-green alga, via inhibition of nuclear factor-kB in RAW264.7 macrophages. Nutr. Res. 2008, 28, 83-91. [CrossRef] [PubMed]

53. Jeong, D.H.; Kim, K.B.W.R.; Kim, M.J.; Kang, B.K.; Ahn, D.H. Skipjack tuna (Katsuwonus pelamis) eyeball oil exerts an anti-inflammatory effect by inhibiting NF-kB and MAPK activation in LPS-induced RAW264.7 cells and croton oil-treated mice. Int. Immunopharmacol. 2016, 40, 50-56. [CrossRef] [PubMed]

54. Chen, L.; Shen, X.; Chen, G.; Cao, X.; Yang, J. A comparative study of the effects upon LPS induced macrophage RAW264.7 inflammation in vitro of the lipids of Hippocampus trimaculatus Leach. J. Oleo Sci. 2015, 64, 1273-1281. [CrossRef] [PubMed]

55. Fernando, I.P.S.; Sanjeewa, K.K.A.; Kim, H.-S.; Kim, S.-Y.; Lee, S.-H.; Lee, W.W.; Jeon, Y.-J. Identification of sterols from the soft coral Dendronephthya gigantea and their anti-inflammatory potential. Environ. Toxicol. Pharmacol. 2017, 55, 37-43. [CrossRef] [PubMed]

56. Banskota, A.H.; Stefanova, R.; Sperker, S.; Lall, S.P.; Craigie, J.S.; Hafting, J.T.; Critchley, A.T. Polar lipids from the marine macroalga Palmaria palmata inhibit lipopolysaccharide-induced nitric oxide production in RAW264.7 macrophage cells. Phytochemistry 2014, 101, 101-108. [CrossRef]

57. Lopes, G.; Daletos, G.; Proksch, P.; Andrade, P.B.; Valentão, P. Anti-inflammatory potential of monogalactosyl diacylglycerols and a monoacylglycerol from the edible brown seaweed Fucus spiralis Linnaeus. Mar. Drugs 2014, 12, 1406-1418. [CrossRef]

58. Ishii, M.; Nakahara, T.; Araho, D.; Murakami, J.; Nishimura, M. Glycolipids from spinach suppress LPS-induced vascular inflammation through eNOS and NK-кB signaling. Biomed. Pharmacother. 2017, 91, 111-120. [CrossRef]

59. Tak, P.P.; Firestein, G.S. NF-kB: A key role in inflammatory diseases. J. Clin. Investig. 2001, 107, 7-11. [CrossRef]

60. McGrath, M.A.; Harnett, M.M.; Thalhamer, T. MAPKs and their relevance to arthritis and inflammation. Rheumatology 2008, 47, 409-414.

61. Zhu, J.; Luo, C.; Wang, P.; He, Q.; Zhou, J.; Peng, H. Saikosaponin A mediates the inflammatory response by inhibiting the MAPK and NF-кB pathways in LPS-stimulated RAW264.7 cells. Exp. Ther. Med. 2013, 5, 1345-1350. [CrossRef]

62. Bligh, E.G.; Dyer, W.J. A rapid method of total lipid extraction and purification. Can. J. Biochem. Phys. 1959, 37, 911-917. [CrossRef] [PubMed]

63. Garces, R.; Mancha, M. One-step lipid extraction and fatty acid methyl esters preparation from fresh plant tissues. Anal. Biochem. 1993, 211, 139-143. [CrossRef] [PubMed]

64. Park, W.J.; Kothapalli, K.S.D.; Lawrence, P.; Tyburczy, C.; Brenna, J.T. An alternate pathway to long-chain polyunsaturates: The FADS2 gene product Delta8-desaturates 20:2n-6 and 20:3n-3. J. Lipid Res. 2009, 50, 1195-1202. [CrossRef] [PubMed] 
65. Kim, J.K.; Cho, M.L.; Karnjanapratum, S.; Shin, I.S.; You, S.G. In vitro and in vivo immunomodulatory activity of sulfated polysaccharides from Enteromorpha prolifera. Int. J. Biol. Macromol. 2011, 49, 1051-1058. [CrossRef]

66. Green, L.C.; Wagner, D.A.; Glogowski, J.; Skipper, P.L.; Wishnok, J.S.; Tannenbaum, S.R. Analysis of nitrate, nitrite, and [15N]nitrate in biological fluids. Anal. Biochem. 1982, 126, 131-138. [CrossRef]

67. Livak, K.J.; Schmittgen, T.D. Analysis of relative gene expression data using real-time quantitative PCR and the $2^{-\Delta \Delta C T}$ method. Methods 2001, 25, 402-408. [CrossRef]

(C) 2020 by the authors. Licensee MDPI, Basel, Switzerland. This article is an open access article distributed under the terms and conditions of the Creative Commons Attribution (CC BY) license (http://creativecommons.org/licenses/by/4.0/). 